\title{
An integrated inundation model for highly developed urban areas
}

\author{
A.S. Chen ${ }^{*}$ M.H. Hsu**, T.S. Chen ${ }^{* *}$ and T.J. Chang** \\ * Flood and Drought Disasters Reduction Division, National Science and Technology Center for \\ Disaster Reduction, 3 F, No. 106, Sec. 2, Hoping E. Rd. Taipei, Chinese Taiwan 106 \\ (E-mail: albertchen@ncdr.nat.gov.tw) \\ ** Dept. of Bioenvironmental Systems Engineering, National Taiwan University, No. 1, Sec. 4, \\ Roosevelt Rd., Taipei, Chinese Taiwan 106 (E-mail: mhhsu@ntu.edu.tw; tschen@ntu.edu.tw; \\ tjchang@ntu.edu.tw)
}

Abstract A numerical model is developed in this study with various components for simulating the complex flow phenomena in urban drainage basins. The model integrates the HEC-1 model, a 1-D dynamic channel-flow model, a 2-D non-inertia overland-flow model and the SWMM model to reflect the hydraulic processes in areas with different characteristics. The inundation of underground infrastructure during flood is also considered in the model. The typhoon Nari event in 2001, which resulted in severe flood in downtown Taipei, is simulated by the model. The result is compared with the survey records of flooded areas, which reveals the storage effect of underground infrastrucures is significant to the simulation results of highly developed urban areas.

Keywords Urban drainage basin; inundation model; underground infrastructure

\section{Introduction}

Flood inundation processes in urban areas are primarily affected by the artificial factors such as drainage facilities, local alterations of topography and land uses. Various numerical models have been developed in the past to simulate flood inundation (Connell et al., 2001; DiGiammarco et al., 1996; Froehlich, 2002; Horritt and Bates, 2002; Swain et al., 2004). However, they consider only overland and channel flows on the ground surface. Several studies investigated the effects of landform changes by the channel-flow or overland-flow models (De Roo et al., 2003; Wheater, 2002; Wiles and Levine, 2002; Wongsa and Shimizu, 2004). Other factors such as sewer systems and underground infrastructures are ignored, although these factors are important to highly developed urban areas.

On the other hand, there are many numerical models built for flow computations in urban sewer systems (DHI Water \& Environment, 2003; Huber and Dickinson, 1988; XP Software Inc., 2002). When the rainfall intensity is under the design criteria of sewer systems, the surface runoff is directly collected by inlets and drained into sewers. The sewer models are sufficient to reflect rainfall-runoff processes in urban areas. However, when the rainfall intensity exceeds the design criteria, the sewer systems are not always capable to carry all the runoff due to the limited capacities of inlets or conduits. As a result, the inundation takes place. The excess water, including the rainfall excess and the surcharged flow from manholes, becomes overland runoff and flows on the surface toward lowlands until it reaches other under-capacity drainage inlets. The complex phenomena cannot be simulated individually by channel flow, overland flow or storm sewer models.

Additionally, the subterranean infrastructures such as subways, underground passages and parking lots are widely constructed for full utilizations in highly urbanized areas. 
Meanwhile, the basements of skyscrapers are commonly used as shopping malls, generator rooms, garages or warehouses. During floods, the infrastructures and basements of buildings in lowlands without adequate defence facilities could be intruded by high raised floods and resulted in heavy losses. The floods often cut off the transportation, swallow the automobiles, overwhelm the properties and destroy the electric power systems. The deep impacts caused by flood hazards usually take weeks, sometimes months, and tremendous budgets for reconstructions.

\section{Methods}

To simulate the complex hydraulic processes in urban areas, an urban inundation model is developed herein by coupling various routing components. The area is divided into upstream catchments, river channels and alluvial plains, according to the geological, hydrological and hydraulic characteristics. The upstream catchments usually have steeper slopes, hence, the surface runoffs concentrate rapidly to channels and flow into downstream alluvial plains when the storm rainfall occurs. The hydrological model is used to calculate the runoffs, which are used as discharge inputs for the downstream alluvial plain. For the river channels which runoffs concentrate to, a 1-D dynamic channel-flow routing is performed for the main channel flow computations. As the alluvial plains with mild natural topography, a 2-D overland-flow routing is used for surface inundation simulations. For the urban regions with detailed sewer drainage systems, a storm sewer model is applied for flow routings in sewerages.

Figure 1 displays the relationships between the routing components and simulation processes. The HEC-1 hydrological model is first routed to simulate the runoff discharges of the upstream catchments, which are considered as the upstream boundary conditions of the downstream hydraulic models, including the 1-D dynamic channel-flow, the 2-D non-inertia overland-flow and the storm sewer-flow models. The flow interactions are set as internal boundary conditions between hydraulic models with the considerations of the corresponding water stages among the models.

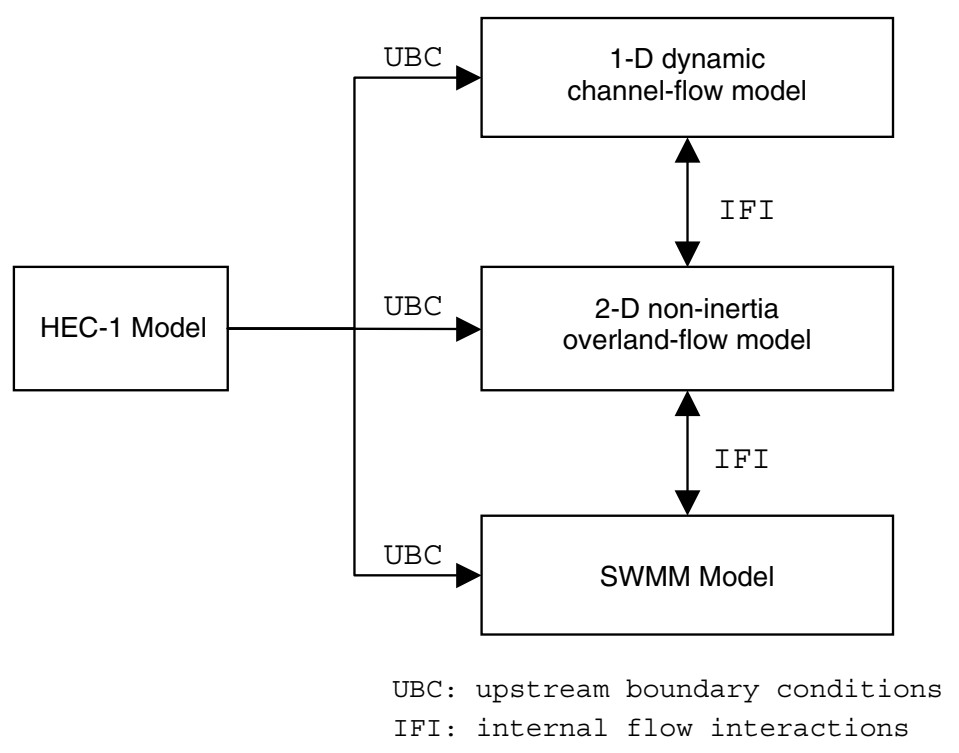




\section{Hydrological model}

The HEC-1 hydrological model, developed by U.S. Army Corps of Engineering (U.S. Army Corps of Engineers Hydrologic Engineering Center, 1992), is used to determine the surface runoffs resulting from effective rainfall in the upstream catchments. The discharges at the outlets of catchments are set as the upstream boundary conditions for the hydraulic routings of downstream plains.

\section{Hydraulic models}

Channel-flow routing. The water flows in channels are solved by the 1-D unsteady gradually varied flow equations as described below (Lai, 1986):

$\frac{\partial A}{\partial t}+\frac{\partial Q}{\partial s}-q_{l 1}+q_{l 2}=0$

$\frac{\partial Q}{\partial t}+\frac{\partial}{\partial s}\left(\frac{Q^{2}}{A}\right)-g A\left(S_{o}-\frac{\partial d}{\partial s}-S_{f}\right)+q_{l 2}\left(\frac{Q}{A}\right)=0$

where, $A$ and $Q=$ the cross-sectional area and discharge of the channel, respectively; $q_{l 1}=$ the lateral inflow per unit length flowing from floodplain to the channel; $q_{l 2}=$ the lateral outflow per unit length flowing from the channel to floodplain; $s=$ the coordinate along longitudinal direction; $g=$ the gravitational acceleration; $S_{0}=$ the bed slope; $d=$ the flow depth; $S_{f}=$ the friction slope and equal to $\left(n_{c}^{2} Q|Q|\right) /\left(A^{2} R^{4 / 3}\right) ; R=$ the hydraulic radius; $n_{c}=$ the Manning's roughness of channel. Eqs. (1) and (2) are solved by the four-point Preissmann scheme (Preissmann, 1961), which have been extensively used to solve the St. Venant equation.

The study assumes that the lateral inflow from the alluvial plain enters the channel without the velocity component along the longitudinal direction of channel. In addition, the lateral outflow from the channel toward alluvial plain is considered carrying the mean velocity component along the longitudinal direction. Both of the lateral inflow and outflow discharges are calculated, which will be explained in the next subsection, according to the linkages between channels and alluvial plains.

Overland-flow routing. A series of studies on the numerical modeling of inundation in Taiwan have been conducted (Hsu, 1992; Hsu et al., 1990). It was concluded that a 2-D noninertia model could accurately simulate the overland flow in alluvial plain due to its slow flow dynamics. The accelerations of the water flow on the land surface are assumed small, comparing to gravity and friction, such that the inertial terms in the St. Venant equation are neglected. The continuity and depth-averaged shallow water equations can be written as (Akan and Yen, 1981):

$$
\begin{aligned}
& \frac{\partial d}{\partial t}+\frac{\partial[(1-\beta) u d]}{\partial x}+\frac{\partial[(1-\beta) v d]}{\partial y}=q_{\text {source }}(x, y, t)-q_{\text {sink }}(x, y, t) \\
& -\frac{\partial h}{\partial x}=S_{f x}+\frac{\left[q_{\text {source }}(x, y, t)\right] u}{g d} \\
& -\frac{\partial h}{\partial y}=S_{f y}+\frac{\left[q_{\text {source }}(x, y, t)\right] v}{g d}
\end{aligned}
$$

where, $d=$ the water depth, $\beta=\sqrt{A_{b} / A}$ detaining ratio which represents a linear ratio of building area to the total area of interest; $u$ and $v$ are the velocity components in the $\mathrm{x}$ and $\mathrm{y}$ directions, respectively; $h=d+z=$ the water surface elevation; $S_{f x}=\left(n^{2} u \sqrt{u^{2}+v^{2}}\right) /\left(d^{4 / 3}\right)$ and $S_{f y}=\left(n^{2} v \sqrt{u^{2}+v^{2}}\right) /\left(d^{4 / 3}\right)$ are the friction slopes along the $x$ and $y$ directions, respectively; $q_{\text {source }}(x, y, t)=$ the rate of water entering ground surface per unit area, 


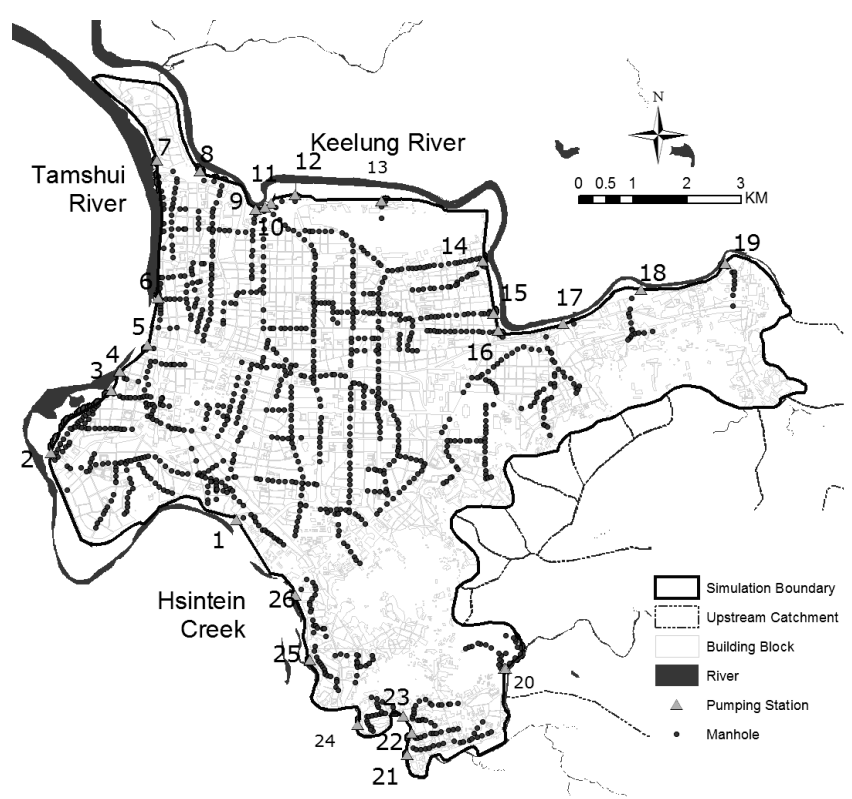

Figure 2 Storm sewer systems and pumping stations of downtown Taipei

including the surcharges from manholes, the upstream catchments inflows and the lateral inflows from channels; $q_{\sin k}(x, y, t)=$ the rate of water leaving ground surface per unit area, including the drainages through inlets into sewers and the lateral outflow to channels. Equations (3) to (5) are solved by a finite-difference numerical scheme, namely alternating direction explicit (ADE), which allows an initial condition with zero water depth and velocity. The derivation of finite difference equations was depicted in the authors' earlier study (Hsu et al., 2000).

Channel-flow and overland-flow model linkage. The interactions between channels and alluvial plains are determined according to the linkage types. The discharges drained by pumping stations or through gates from alluvial plain to channels are regarded as the lateral outflows of the 2-D model, by contrast, as the lateral inflow of the 1-D model.

If the channel flow intrudes into alluvial plain through gates because of the higher channel water stage, the discharge is considered as the lateral inflow of the 2-D model and the lateral outflow of the 1-D model. On the other hand, if the water stage in the channel or on the

Table 1 The total amount and peak intensity of rainfall in downtown Taipei during typhoon Nari

\begin{tabular}{lcc}
\hline Gauge name & $\begin{array}{c}\text { Total rainfall } \\
(\mathbf{m m})\end{array}$ & $\begin{array}{c}\text { Peak intensity } \\
(\mathbf{m m} / \mathbf{h})\end{array}$ \\
\hline Shihlin & 576.0 & 94.0 \\
Sunchun & 554.0 & 68.0 \\
Taipei & 618.0 & 77.0 \\
Chungcheng Bridge & 630.0 & 95.0 \\
Yunghon & 565.0 & 93.5 \\
Mucha & 669.5 & 57.5 \\
Shinyi & 549.0 & 84.5 \\
Nankang & 787.0 & 105.0 \\
Tachih & 629.5 & 93.5 \\
Neihu & 732.0 & 109.5 \\
\hline
\end{tabular}




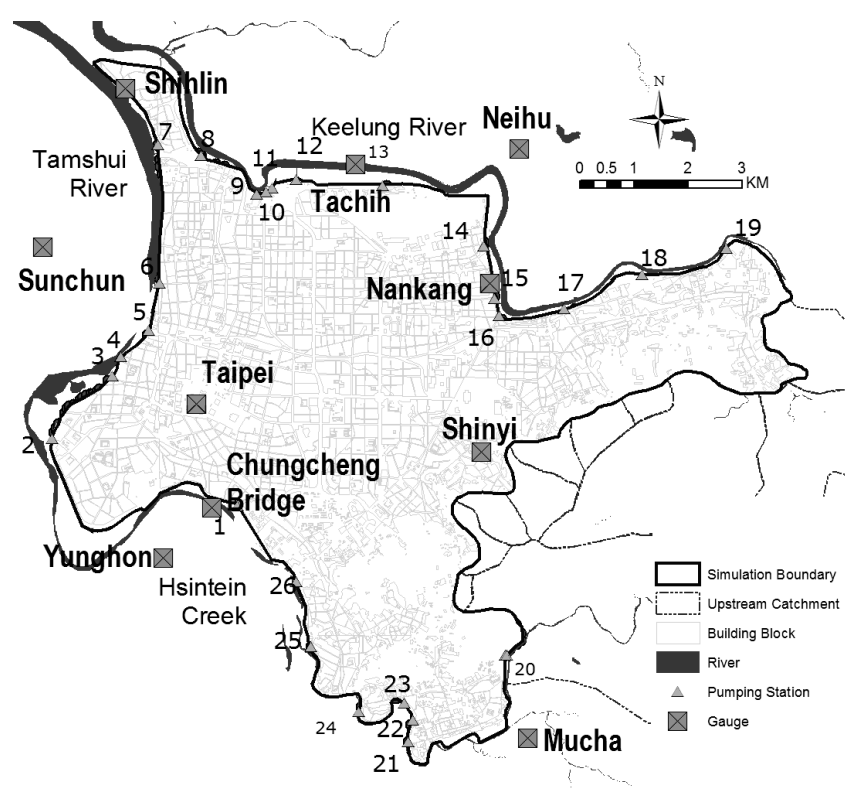

Figure 3 The locations of rainfall gauges in downtown Taipei

overland surface exceeds the top elevation of levee, the discharge flowing over the levee is computed by the weir-discharge equations based on the water stage excess.

Urban drainage routing. The SWMM developed by the EPA is considered as the most authoritative and popular model for solving water flow in storm sewer networks. It has been adopted by different commercial software, including MIKE SWMM (DHI Water \& Environment, 2002), PC SWMM (Computational Hydraulics Int., 2002) and XP SWMM (XP Software Inc., 2002), as the kernel engine for computing. The detailed governing equations and numerical schemes could be found in EPA's documents (Huber and Dickinson, 1988).

The source code of SWMM is modified in the current study by combining the overlandflow and storm sewer models. The overflow from surcharged manhole is calculated by SWMM and considered as a point source in overland-flow routing. On the other hand, the inlet discharge is computed as a point sink in the overland-flow model. It is deemed as lateral

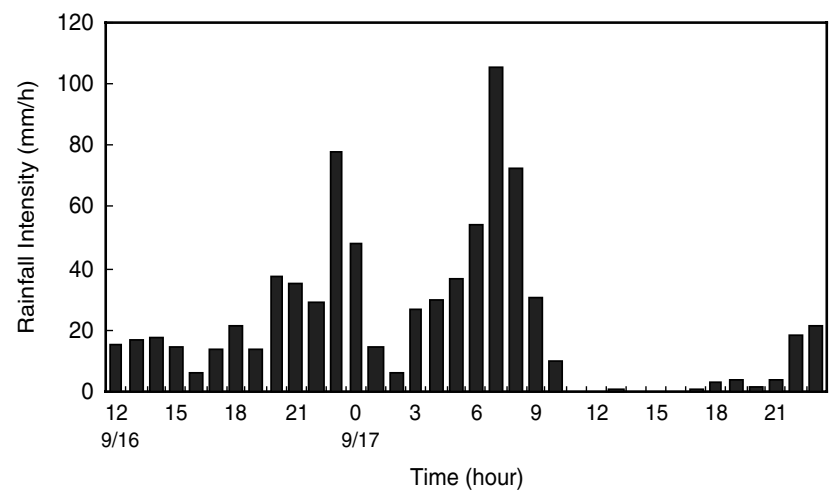

Figure 4 The hyetograph of Nankang gauge during typhoon Nari 


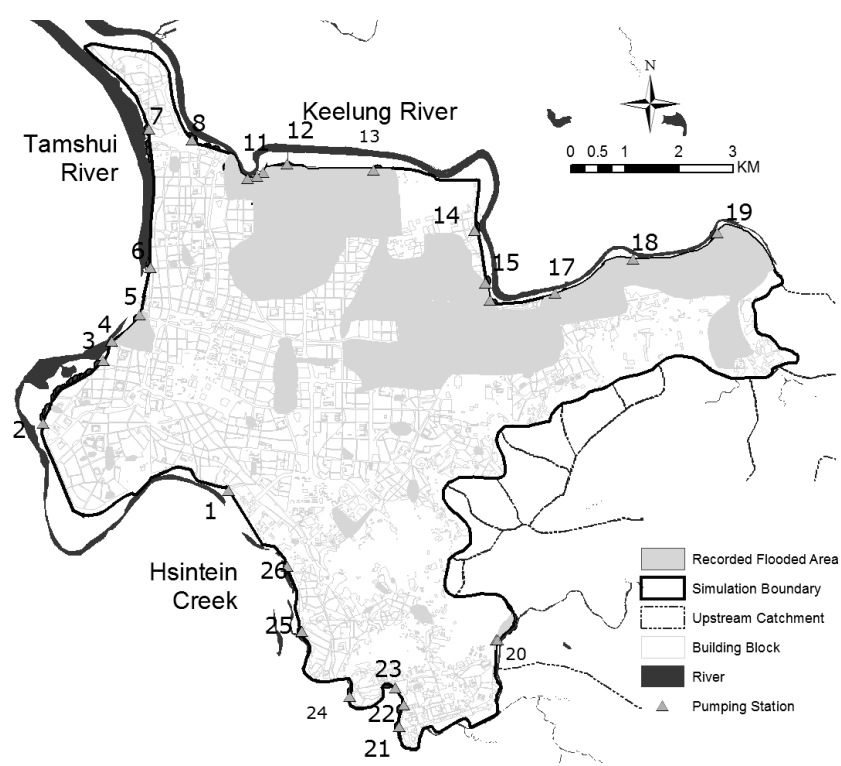

Figure 5 Investigated flooded areas of typhoon Nari in downtown Taipei

inflow in the SWMM for imposing the overland runoff into the sewer system. The detailed description of the interactions between the sewer flow and the overland flow models can be found in the authors' previous publication (Hsu et al., 2002).

Storage effect of underground infrastructures. The storage effects of underground infrastructures are considered in our overland-flow routings. When the water stage of overland flow is higher than the entrance of subterranean infrastructure, which has no flood-proofing gate, the flow is flowing toward the underground basement through the entrance. The discharge is determined by the weir equation when the space in subterranean building is

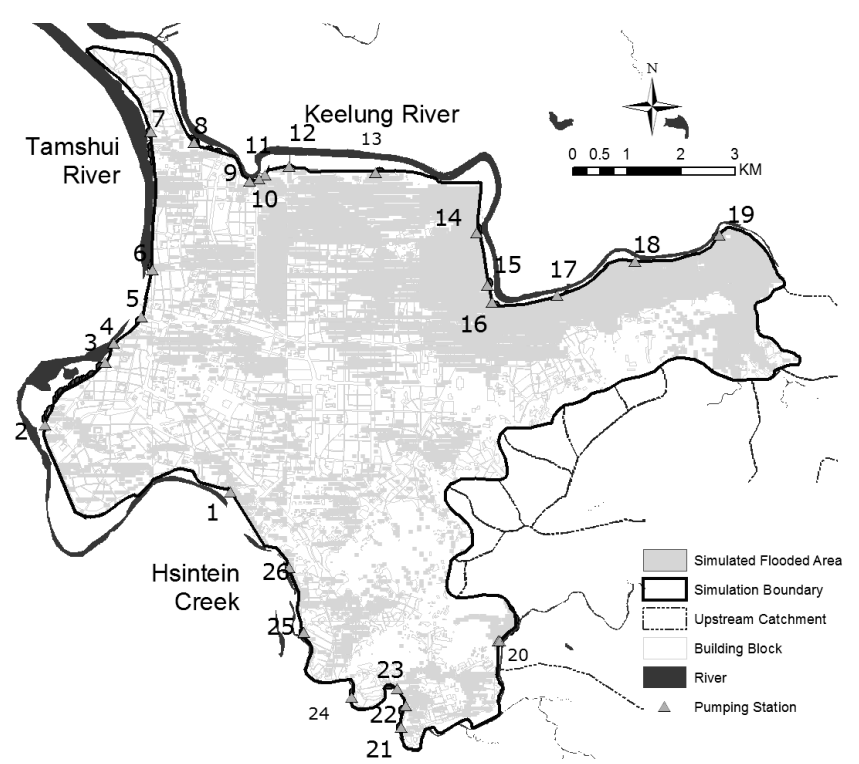


Table 2 The recorded and simulated failing time pumping stations in downtown Taipei during typhoon Nari

\begin{tabular}{lccc}
\hline No. & Design capacity (cms) & Failing time \\
& & Recorded & Simulated \\
\hline 20 & 20.0 & $09 / 1623: 23$ & $09 / 1623: 26$ \\
19 & 20.0 & $09 / 1700: 19$ & $09 / 1700: 14$ \\
18 & 32.0 & $09 / 1704: 00$ & $09 / 1703: 53$ \\
13 & 32.0 & $09 / 1708: 00$ & $09 / 1708: 02$ \\
17 & 184.1 & $09 / 1709: 00$ & $09 / 1708: 56$ \\
\hline
\end{tabular}

available. If the underground infrastructure is fully submerged, the discharge is set as zero. The basement has become a retention pond and the deluge is trapped inside until being pumped out after the flood.

\section{Results and discussion}

The downtown Taipei is densely populated and highly developed as the political and financial center of Taiwan. It is surrounded by the Tamshui River on the west, the Hsintein Creek on the south, the Keelung River on the north and hills on the southeast and east. It is protected by the high-raised levees along the rivers and dozens of pumping stations, as shown in Figure 2, which were built for flood control. However, on 16 and 17 September 2001, the typhoon Nari swept through Taiwan with a historical-high rainfall record in northern Taiwan. Table 1 shows the total amount and peak intensity of rainfall records of the gauges in downtown Taipei during typhoon Nari. The locations of gauges are shown in Figure 3. The rainfall concentrated in the neighborhood of Nankang and Neihu gauges was more than 700 $\mathrm{mm}$ in 36 hours. Figure 4 displays the hyetograph of Nankang gauge, during the event. The peak intensity was more than $105 \mathrm{~mm} / \mathrm{h}$ and exceeded the design standard, which is $78 \mathrm{~mm} / \mathrm{h}$, of the sewer systems in Taipea City.

The torrential rainfall caused the most serious flood damage of Taipei in decades. The flash flood of the Keelung River flowed from a levee gap near the pumping station No. 19 and flooded the downtown Taipei. Many pumping stations, Nos. 13, 17, 18, 19 and 20, were submerged by flooding water, and were paralysed. Among these failed stations, the $\mathrm{Yu}$-Cheng station (No. 17), which is the largest pumping station in the Southeast Asia with the design capacity of $184 \mathrm{cms}$, caused very serious damage.

Figure 5 shows the flooded areas, which are more than $30 \mathrm{~cm}$ in water depth and marked in dark color, release by the Taipei City Government (Taipei City Government, 2001). The inundated area was about 1,986 hectares. The blank area nearby pumping station 14 as shown in Figure 5 was actually flooded according to the media reports. The reason why this area was not marked in dark color was because the city government was not allowed to conduct the survey in this area which belongs to a military airport. The lowlands along the Keelung River were almost inundated entirely. Thousands of building basements and the two subway

Table 3 The pumped and simulated water volumes in subway systems in downtown Taipei during typhoon Nari

\begin{tabular}{lcc}
\hline System & $\begin{array}{c}\text { Pumped water vol. } \\
\left(\times 1 \mathbf{1}^{3} \mathbf{~ m}^{\mathbf{3}}\right)\end{array}$ & $\begin{array}{c}\text { Simulated flood water } \\
\text { vol. }\left(\times \mathbf{1 0}^{3} \mathbf{~ m}^{\mathbf{3}}\right)\end{array}$ \\
\hline TRTS \& MRTS Red Line & 1,012 & 950 \\
MRTS Blue Line & 390 & 406 \\
\hline
\end{tabular}


systems, the TRTS (Taipei Rail Transit System) and the MRTS (Mass Rapid Transit System), were filled by the deluge. It took a few weeks to pump all the water out from the basements and took three months to rehabilitate the MRTS completely. The total amount of damage was estimated to be NT\$ 1.36 billions (Chang, 2004). For most Taipei citizens, it was inconvenient during the days without a well-functioning MRTS.

The hourly rainfall records of the gauges are input in the numerical simulation. The total simulated flooded areas are 2,108 hectares and shown in Figure 6. The calculated flooded area within the above-mentioned military airport is 124 hectares, which is close to the difference between the surveyed, by the Taipei City Government, and our simulated flooded areas. Table 2 compares the actually recorded and our simulated failing time of pumping stations. The simulation result shows that the sewers collected great amounts of surface runoffs and directed the flows to the pumping stations, however, the pumping stations were incapable to drain the excess water immediately. Thus, the areas nearby were seriously inundated and the flood extended to neighborhoods quickly. Most basements of buildings and facilities in the areas, including the TRTS and MRTS which have no flood-proof gates were hence devoured by the unexpected flash flood. The flood volume that entered the subway systems was estimated by the pupming records after the event. The pumped water volume from the TRTS and MRTS Red Line systems, which are connected to each other, was about $1,012 \times 10^{3} \mathrm{~m}^{3}$ and the water volume of MRTS Blue Line system was $390 \times 10^{3} \mathrm{~m}^{3}$. The simulated flood intrusions in the two systems were $950 \times 10^{3} \mathrm{~m}^{3}$ and $406 \times 10^{3} \mathrm{~m}^{3}$, respectively (see Table 3 ). The simulation results are consistent with the survey records released by the Taipei City Government. It must be noted that if the storage effect of the underground infrastructures was not considered in the numerical simulation, the flooded areas would be over-estimated.

\section{Conclusion}

An urban inundation model is developed in this article to simulate the dynamic flow interactions among the channels, sewer systems, underground infrastructures and alluvial plains. The precipitation records of typhoon Nari are used for model simulation. The simulated flooded area, failing time of pumping station and flood volume in subway systems are compared to the actually recorded ones. The results indicate that our proposed model, which considers the storage effect of the underground infrastructures, can properly reflect the complex flow phenomena in urban drainage basins.

\section{References}

Akan, A.O. and Yen, B.C. (1981). Mathematical Model of Shallow Water Flow Over Porous Media, Journal of the Hydraulics Division, ASCE, 107(HY4), 479-494.

Chang, H.K. (2004). Disaster recovery and management of Taipei Metro after typhoon Nari, The 2nd Asian crisis management conference, Taipei Fire Department, II-157-II-187, Taipei, Taiwan.

Computational Hydraulics Int. (2002). Introduction for PCSWMM 2002, http://www. computationalhydraulics.com/pcswmm.html, Guelph, Ontario, Canada.

Connell, R.J., Painter, D.J. and Beffa, C. (2001). Two-dimensional flood plain flow. II: Model validation, Journal of Hydrologic Engineering, 6(5), 406-415.

De Roo, A., Schmuck, G., Perdigao, V. and Thielen, J. (2003). The influence of historic land use changes and future planned land use scenarios on floods in the Oder catchment, Physics and Chemistry of the Earth, 28(33-36), 1291-1300.

DHI Water \& Environment (2002). MIKE SWMM - the new generation SWMM, DHI Software, Hørshølm, Denmark.

DHI Water \& Environment (2003). MOUSE Pipe Flow, Reference Manual, DHI Software, Hørshølm, Denmark. 
DiGiammarco, P., Todini, E. and Lamberti, P. (1996). A conservative finite elements approach to overland flow: The control volume finite element formulation, Journal of Hydrology, 175(1-4), 267-291.

Froehlich, D.C. (2002). User's Manual for FESWMS Flo2DH, Two-dimensional Depth-averaged Flow and Sediment Transport Model, Release 3, Federal Highway Administration, McLean, Virginia.

Horritt, M.S. and Bates, P.D. (2002). Evaluation of 1D and 2D numerical models for predicting river flood inundation, Journal of Hydrology, 268(1-4), 87-99.

Hsu, M.H. (1992). Simulation of Inundation with Overflow on Levee along Keelung River, The CCNAA-AIT Joint Seminar on Prediction and Damage Mitigation of Meteorologically Induced Natural Disasters, Taipei, Taiwan.

Hsu, M.H., Chen, S.H. and Chang, T.J. (2000). Inundation Simulation for Urban Drainage Basin with Storm Sewer System, Journal of Hydrology, 234(1-2), 21-37.

Hsu, M.H., Chen, S.H. and Chang, T.J. (2002). Dynamic Inundation Simulation of Storm Water Interaction between Sewer System and Overland Flows, Journal of the Chinese Institute of Engineers, 25(2), 171-177.

Hsu, M.H., Lai, J.S. and Yen, C.L. (1990). Two-dimensional inundation model for Taipei City, Proceedings of the Fifth International Conference on Urban Storm Drainage, Osaka, Japan.

Huber, W.C. and Dickinson, R.E. (1988). Storm Water Management Model. User's Manual Ver. IV, U. S. Environmental Protection Agency.

Lai, C.T. (1986). Numerical Modeling on Unsteady Open-Channel Flow, In Advances in Hydroscience, edited by Yen, B.C., 189-250, Academic Press, New York.

Preissmann, A. (1961). Propagation des intumescences dans les canaux et rivieres, First Congress of the French Association for Computation, Grenoble, France.

Swain, E.D., Wolfert, M.A., Bales, J.D. and Goodwin, C.R. (2004). Two-Dimensional Hydrodynamic Simulation of Surface-Water Flow and Transport to Florida Bay Through the Southern Inland and Coastal Systems (SICS), ed., Pages, U.S. Department of the Interior and U.S. Geological Survey, Tallahassee, Florida.

Taipei City Government (2001). The reconstruction plan for the damage caused by typhoon Nari. Taipei City Government, Taipei, Taiwan.

U.S. Army Corps of Engineers Hydrologic Engineering Center (1992). HEC-1 Hydrograph Package. Water Resources Support Center, Davis, California.z

Wheater, H.S. (2002). Progress in and prospects for fluvial flood modelling, Philosophical Transactions of the Royal Society of London Series a-Mathematical Physical and Engineering Sciences, 360(1796), 1409-1431.

Wiles, J.J. and Levine, N.S. (2002). A combined GIS and HEC model for the analysis of the effect of urbanization on flooding: The Swan Creek watershed, Ohio, Environmental \& Engineering Geoscience, 8(1), 47-61.

Wongsa, S. and Shimizu, Y. (2004). Modelling artificial channel and land-use changes and their impact on floods and sediment yield to the Ishikari basin, Hydrological Processes, 18(10), 1837-1852.

XP Software Inc. (2002). XP-SWMM Technical Description, http://www.xpsoftware.com.au/products/pdfs/ SWMMTech\%20Description.pdf, Portland, Oregon, USA. 
